\title{
CLEMENS ALEXANDRINUS BAND III
}

\section{Einleitung}

Seite

A. Orthographie der Handschrift Laur. V 3 . . . . . . . . . IX

B. Verzeichnis der Stellen des III. Bandes, die auf Grund von L von der Ausgabe Dindorfs abweichen

XVII

C. Bemerkungen zu Quis dives salvetur. . . . . . . . . . . XVII

D. Bemerkungen zu den Fragnenten. . . . . . . . . . . . XXVII

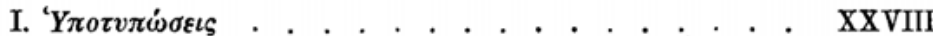

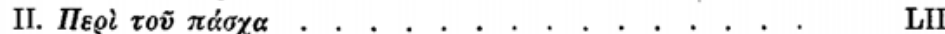

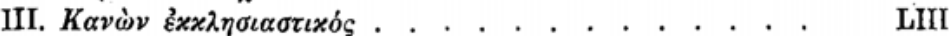

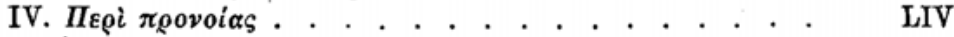

V. 'O

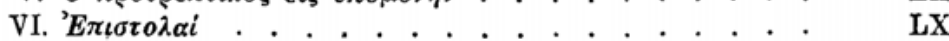

VII. Schriften, von denen keine Fragmente erhalten sind . . IIXIII

VIII. "Beabsichtigte" Schriften . . . . . . . . . . . . LXIII

IX. Fragmente ungewisser Herkunft. . . . . . . . . . LXV

X. Unechte Fragmente . . . . . . . . . . . . . . LXXI

E. Vergleich der Seitenzahlen der Ausgabe des D. Heinsius (Paris 1629) mit denen der vorliegenden Ausgabe . . . . . . . . . . LXXXIV

Schlußwort des Herausgebers. . . . . . . . . . . . . . . LXXXIX

Text

Stromata VII. Buch . . . . . . . . . . . . . . . . . . 1

” VIII. Buch . . . . . . . . . . . . . . . . . . . 80

Excerpta ex Theodoto . . . . . . . . . . . . . . . . . . . 103

Eclogae propheticae . . . . . . . . . . . . . . . . . . 135

Quis dives salvetur . . . . . . . . . . . . . . . . . . 157

Fragmente . . . . . . . . . . . . . . . . . 193

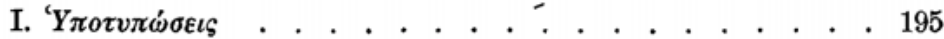

II. $\Pi_{\varepsilon \varrho l} \tau o \tilde{v} \pi \dot{\alpha} \sigma \chi \alpha \quad$. . . . . . . . . . . . . . . . . . . . . . . . . 216

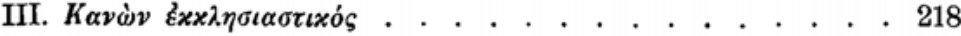

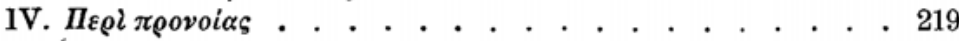

V. 'O

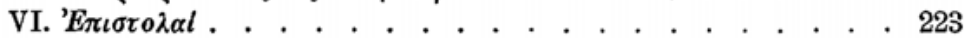

VII. Fragmente ungewisser Herkunft . . . . . . . . . . . 224

Nachträge und Berichtigungen. . . . . . . . . . . . . . . . . . 231

Facsimile von Paris. graec. 451 f. $6^{\mathbf{v}}$. . . . . . . . . . . . Tafel I

Laur. V 3 f. $228^{v}$. . . . . . . . . . . . . . , " II

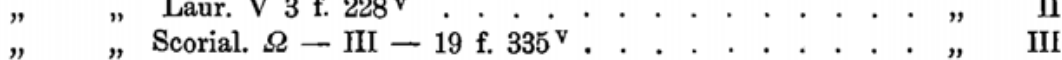


